20 Sharp CL, Butterfield WJH, Keen H. Diabetes survey in Bedford 1962. Proc $R$ Soc Med 1964;57:193.

21 Shaper AG, Pocock SJ, Walker M, Cohern NM, Wale CJ, Thomson AG. British regional heart study: cardiovascular risk factors in middle-aged men in 24 towns. BM7 1981;283:179.

22 Winocour PH, Harland JOE, Millar JP, Laker MF, Alberti KGMM Microalbuminuria and associated cardiovascular risk factors in the community. Atherosclerosis 1992;93:71-81.

23 Harris MI, Hadden WC, Knowler WC, Bennett PH. International criteria for the diagnosis of diabetes and impaired glucose tolerance. Diabetes Care 1985;8:562-7.

24 Farrer M, Game FL, Adams PC, Laker MF, Alberti KGMM. A simple, sensitive technique for classification of apolipoprotein(a) isoforms by sodium dodecyl sulphate-polyacrylamide gel electrophoresis. Clin Chim Acta 1992;207:215-25.

25 Fontbonne A, Eschwege E, Cambien F. Hypertriglyceridaemia as a risk factor of coronary heart disease mortality in subjects with impaired glucose tolerance or diabetes. Results from 11-year follow-up of the Paris prospective study. Diabetologia 1989;32:300-4.

26 Stamler R, Stamler J, eds. Asymptomatic hyperglycaemia and coronary hear disease. 7 Chronic Dis 1979;32:683-837.

27 Modan M, Hilken H, Lusky A, Segal P, Fuchs Z, Chetrit A. Hyperinsulinaemia is characterized by jointly disturbed plasma VLDL, LDL, and HDL levels. Arteriosclerosis 1988;8:227-36.

28 Howard BV, Knowler WC, Vasquez B, Kennedy AL, Pettitt DJ, Bennett PH. Plasma and lipoprotein cholesterol and triglycerides in the Pima Indian population. Arteriosclerosis 1984;4:462-71.
29 Abrams ME, Jarrett RJ, Keen H, Boyns DR, Crossley JN. Oral glucose tolerance and related factors in a normal population sample. II: Interrelationship of glycerides, cholesterol and other factors with the glucose and

Zavaroni I, Dall'Aglio E, Bonora E, Alpi O, Passeri M, Reaven GM. Evidence that multiple risk factors for coronary artery disease exist in persons with

31 Capaldo B, Tutino L, Patti L, Vaccaro O, Rivellese A, Ricardi G. Lipoprotein composition in individuals with impaired glucose tolerance. Diabetes Care 1983;6:575-8.

32 Vaccaro O, Rivellese A, Ricardi G, Capaldo B, Tutino L, Annuzi G, et al. Impaired glucose tolerance and risk factors for atherosclerosis. Arteriosclerosis 1984;4:592-6.

33 Lillioja S, Mott DM, Howard BV. Impaired glucose tolerance as a disorder of insulin action: longitudinal and cross-sectional studies in Pima Indians. N Engl F Med 1988;318:1217-25.

34 Lillioja S, Mott DM, Zawadzki JK. In vivo insulin action is familial characteristic in nondiabetic Pima Indians. Diabetes 1987;36:1329-35.

35 O'Rahilly SP, Nugent Z, Rudenski AS. Beta-cell dysfunction, rather than insulin insensitivity, is the primary defect in familial type 2 diabetes. Lancet 1986;ii:360-4.

36 Eriksson J, Franssila-Kallunki A, Ekstrand A, Saloranta C, Widen E, Schalin $\mathrm{C}$, et al. Early metabolic defects in persons at increased risk for non-insulindependent diabetes mellitus. N Engl $\mathcal{F}$ Med 1989;321:337-43.

(Accepted 12 August 1993)

\title{
Measuring the impact of menopausal symptoms on quality of life
}

\author{
Edel Daly, Alastair Gray, David Barlow, Klim McPherson, Monica Roche, Martin Vessey
}

\section{Abstract}

Objective-To examine the impact of menopausal symptoms on the overall quality of life of women.

Design-Data collection with a questionnaire administered by an interviewer, incorporating two different quality of life measurement techniques (time trade off and rating scale).

Setting-Specialist menopause clinic and two general practices in Oxford.

Subjects -63 women aged 45-60 years recruited opportunistically during a clinic or appointment with a general practitioner; no exclusion criteria.

Results-Subjects gave very low quality of life ratings for health states with menopausal symptoms. The time trade off method of measuring preferences for these health states (on a scale from 0 to 1 , where preference for full health is given as 1) yielded utility values of $\mathbf{0 . 6 4}$ for severe menopausal symptoms and 0.85 for mild symptoms. The rating scale measurement technique yielded even lower values: utilities of 0.30 and 0.65 were obtained for severe and mild symptoms respectively. Kappa scores indicated that the two methods produced results that were poorly related but not contradictory. Comparison of quality of life ratings before and after treatment with hormone replacement therapy showed significant improvements: with the rating scale measurement technique mean increases in utility values after the relief of severe and mild menopausal symptoms were 0.56 and 0.18 respectively.

Conclusions-Quality of life may be severely compromised in women with menopausal symptoms, and perceived improvements in quality of life in users of hormone replacement therapy seem to be substantial. This emphasises the need to include quality of life measurements when assessing outcomes of hormone replacement therapy. Several limitations may exist with widely applied measurement techniques, calling for the development of appropriate and well validated instruments for measuring quality of life associated with reduced health states.

\section{Introduction}

In recent years there has been much interest in hormone replacement therapy and the overall balance of benefits and risks. ${ }^{1-3}$ One benefit of hormone replacement therapy is its proved effect in alleviating menopausal symptoms ${ }^{49}$ - symptoms which persist for more than one year in over $80 \%$ of menopausal women. ${ }^{10} \mathrm{Few}$ attempts have been made to measure the impact of menopausal symptoms on quality of life or changes in quality of life resulting from use of hormone replacement therapy. In a cost effectiveness study of hormone replacement therapy carried out in the United States, adjustments for quality of life were based on the authors' own judgments rather than on evidence. ${ }^{11}$ Here we report some fieldwork to assess the impact of menopausal symptoms on quality of life, involving a questionnaire based interview of 63 women aged between 45 and 60 . The objective was to derive a quantitative measure of the value or "utility" placed by women on quality of life states associated with menopausal symptoms. The fieldwork was undertaken as part of a cost effectiveness study in which the outcome of hormone replacement therapy was expressed in terms of quality adjusted life years, or QALYs, an outcome measure which strives to combine the change in quality of life associated with an intervention with the change in life expectancy.

\section{Methods}

Several methods exist to measure quality of life..$^{12-14}$ We decided to use two valuation methods and to compare the results obtained from each. Firstly, subjects were given descriptions of menopausal symptoms and shown a simple visual numerical scale of 0 to 10 with defined end points of death and normal health. They were asked to pick a point on the scale that reflected the quality of life associated with the health state in question. We will refer to this as the rating scale method.

Secondly, subjects were given the same descriptions of menopausal symptoms and invited to enter a procedure for the valuation of health states known as the time trade off method, again supported by a visual illustration. This method has been applied widely in the United States for the evaluation of health states. ${ }^{12}$ It has been argued that this method has advantages in terms of ease of application and consistency of result, ${ }^{15} 16$ especially where the disease under investigation is chronic or does not involve life threatening 
risks. ${ }^{17}$ The approach involves offering the subject two alternatives - a number of years ( $x$ ) of life lived at reduced health (which is defined) or fewer years (y) of life lived at normal health. Time $y$ is varied until the subject has no preference for one alternative over the other, at which point the utility value associated with the state of reduced health is given by $y / x$.

The questionnaire was administered to a sample of women recruited from a specialist menopause clinic (32 women) and two general practices in Oxford (31 women). All women were interviewed by the same interviewer (ED) either directly before or after their consultation with the clinic doctor or their general practitioner. The only criterion for eligibility was that women were aged between 45 and 60 . Women were asked to listen to short non-technical descriptions of typical mild and severe menopausal symptoms and were then asked to indicate their quantitative judgment of the effect these symptoms would have on their overall quality of life. These descriptions, prepared by one of us (DB) on the basis of clinical experience and existing literature, ${ }^{18}$ are reproduced in the appendix.

After the description of mild symptoms had been read out the subject was shown the rating scale and asked: "How would you rate your overall quality of life if you were experiencing these symptoms: the scale runs from 0 to 10 , with 10 being equivalent to normal health and 0 to being dead." This question was then repeated for the description of severe symptoms. Next, the two descriptions were reread, and questions based on the time trade off approach were asked once the principles of the approach had been explained. These questions typically took the form of: "What would you choose between five years with menopausal symptoms and a lesser number of years of normal health?" The last part of the questionnaire included some general questions relating to the woman's history of menopausal symptoms and her use of hormone replacement therapy. Women who had experienced symptoms were also asked if the relevant description (mild or severe symptoms) reasonably matched their own experience.

\section{ANALYSIS}

The sample was divided into three subgroups on the basis of use of hormone replacement therapy and whether women had experienced mild or severe menopausal symptoms: never users of hormone replacement therapy (21 women); hormone replacement therapy users (past or current) who classed themselves as having experienced mild symptoms (17 women); and hormone replacement therapy users (past or current) who classed themselves as having experienced severe symptoms ( 25 women). Of the 21 women who had never used hormone replacement therapy, 16 considered themselves to have experienced mild menopausal symptons, four considered themselves to have experienced severe symptoms, and one reported never having had symptoms.

\section{Results}

The mean age of the sample was 52.1 years (with mean ages ranging between 51.8 and 52.8 years across the three subgroups). Nine out of 31 women recruited at either of the two general practices were consulting their general practitioner in connection with the menopause, while all women recruited at the menopause clinic were seeking advice or treatment in relation to symptoms. All who had suffered with menopausal symptoms felt that our descriptions reasonably reflected their own experience. Table I shows average utility values which were calculated from rating scale scores given in response to the two descriptions. These values, which indicate a surprisingly low quality of life associated with menopausal
TABLE I-Average utility values (95\% confidence intervals) calculated from rating scale scores for mild and severe symptoms given by women grouped by use of hormone replacement therapy and severity of symptoms

\begin{tabular}{lcc}
\hline & \multicolumn{2}{c}{ Symptoms } \\
\cline { 2 - 3 } & \multicolumn{1}{c}{ Mild } & Severe \\
\hline Non-users $(n=21)$ & 0.67 & 0.31 \\
& $(0.60$ to 0.74$)$ & $(0.24$ to 0.38$)$ \\
Users (mild symptoms) $(n=17)$ & 0.64 & 0.32 \\
Users (severe symptoms) $(n=25)$ & $(0.56$ to 0.72$)$ & $(0.23$ to 0.41$)$ \\
& 0.64 & 0.28 \\
All ( $n=63)$ & $(0.57$ to 0.71$)$ & $(0.21$ to 0.35$)$ \\
& 0.65 & 0.30 \\
& $(0.61$ to 0.69$)$ & $(0.26$ to 0.34$)$
\end{tabular}

symptoms, are comparable across the three subgroups.

Table II summarises utility values calculated from responses to the time trade off questions. Here overall values are substantially higher (that is, menopausal symptoms are seen to have less impact on overall quality of life) than those obtained from the rating scale method. A utility value of 0.85 overall was obtained for mild symptoms and a value of 0.64 for severe symptoms - that is, women had no preference for 5 years of mild menopausal symptoms over 4.25 years in normal health, or for 5 years of severe menopausal symptoms over $3 \cdot 2$ years in normal health. In the time trade off approach women are actually being asked, albeit hypothetically, to give up something, whereas the rating scale method simply involves choosing a point on a scale, with no further consequences; hence the answers from the time trade off approach may be a truer reflection of the perceived reduction in quality of life associated with menopausal symptoms.

TABLE I-Average utility values calculated from time trade off scores for mild and severe symptoms given by women grouped by use of hormone replacement therapy and severity of symptoms.

\begin{tabular}{lcc}
\hline & \multicolumn{2}{c}{ Symptoms } \\
\cline { 2 - 3 } & \multicolumn{1}{c}{ Mild } & Severe \\
\hline Non-users (n=21) & 0.86 & 0.75 \\
& $(0.76$ to 0.96$)$ & $(0.64$ to 0.86$)$ \\
Users (mild symptoms) $(n=17)$ & 0.89 & 0.63 \\
& $(0.82$ to 0.96$)$ & $(0.48$ to 0.78$)$ \\
Users (severe symptoms) $(n=25)$ & 0.83 & 0.54 \\
All (n=63) & $(0.73$ to 0.93$)$ & $(0.41$ to 0.67$)$ \\
& 0.85 & 0.64 \\
& $(0.80$ to 0.90$)$ & $(0.57$ to 0.71$)$ \\
& &
\end{tabular}

With regard to the description of severe menopausal symptoms, women using hormone replacement therapy who had classed themselves as having experienced severe symptoms were willing to trade off more length for quality of life than those who had never used hormone replacement therapy (utility values of 0.54 and 0.75 respectively for a health state with severe symptoms). This is shown in the figure, which summarises results obtained from the two methods for each of the three subgroups. Several women were unwilling to make any trade off between length and quality of life, especially in relation to the standard description of mild symptoms. Among women intercepted at the clinic, eight out of 21 "severe sufferers" (self rated) gave a "no time trade off" response when asked about mild symptoms, while three out of 11 "mild sufferers" were unwilling to accept any (hypothetical) reduction in length of life as a trade off for relief of mild symptoms. Among those recruited from general practice, three out of seven severe sufferers and 13 out of 23 mild sufferers were unwilling to trade off length for quality of life. These subjects were included in the analysis.

Current or ever users of hormone replacement therapy were asked to rate their own quality of life (using the rating scale method) before treatment and 


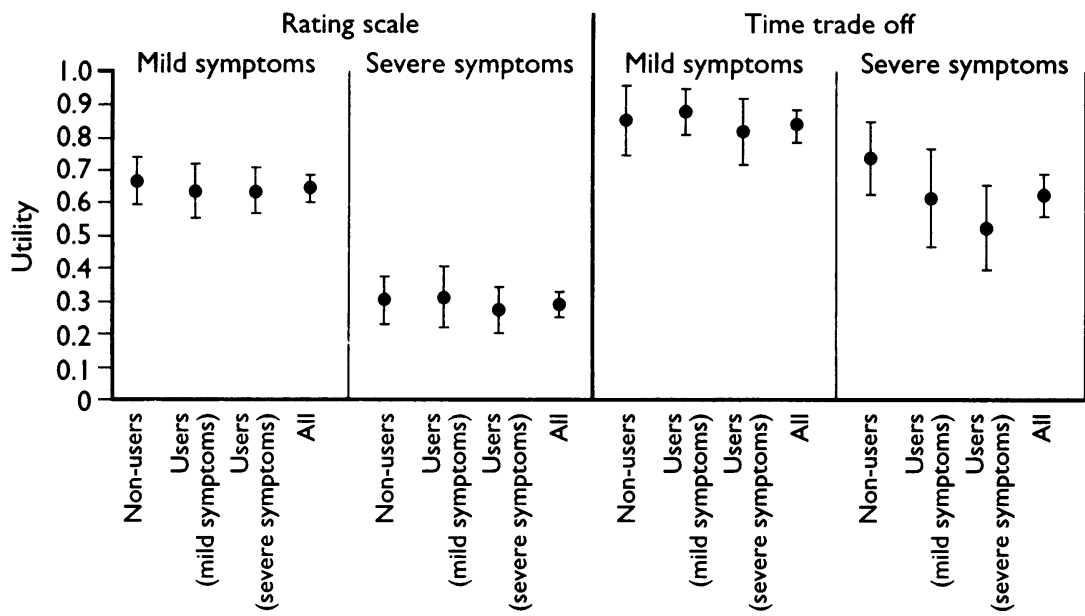

Quality of life valuations grouped by use of hormone replacement therapy and severity of symptoms. Circles are means; bars indicate $95 \%$ confidence intervals

while receiving treatment. As table III illustrates, quality of life ratings significantly improved, especially for women who considered themselves to have experienced severe symptoms, the mean increase in the utility value being $0 \cdot 56$. For users with mild symptoms this increase was $0 \cdot 18$. Two out of 42 users reported a reduction in overall quality of life while receiving treatment, but these women had received treatment for less than six months.

Because the women who participated in the study were recruited opportunistically and anonymously it was not possible to test the reproducibility of the results by asking the same women to complete the questionnaire again at a later date. However, the responses seemed to be internally consistent: all respondents scored severe symptoms lower than mild symptoms, and the average scores given for actual quality of life before hormone replacement therapy (table III) were almost identical to the corresponding scores for the descriptions of mild or severe symptoms (table I).

Table IV shows measures of agreement between results obtained from the two different methods (time trade off and rating scale) in the form of kappa scores. Kappa measures agreement beyond that expected by chance and has a value between 1.00 (perfect agreement and -1.00 (perfect disagreement), with zero indicating no agreement. ${ }^{19}$ Across the sample as a whole there were no significant kappa scores for the two measures of mild symptoms, but the results for severe symptoms showed a weak relation, which was

TABLE III-Average utility values calculated from rating scale scores for quality of life before and after treatment with hormone replacement therapy (HRT) given by women grouped by severity of symptoms

\begin{tabular}{lcc}
\hline & Before HRT & After HRT \\
\hline Users (mild symptoms) $(n=17)$ & 0.61 & 0.79 \\
& $(0.53$ to 0.69$)$ & $(0.69$ to 0.89$)$ \\
Users (severe symptoms) $(\mathrm{n}=25)$ & 0.29 & 0.85 \\
& $(0.20$ to 0.38$)$ & $(0.78$ to 0.92$)$ \\
0.53 & 0.80 \\
All ( $\mathrm{n}=42)$ & $(0.46$ to 0.60$)$ & $(0.71$ to 0.89$)$ \\
& &
\end{tabular}

TABLE IV-Measure of agreement (kappa score and p value) between quality of life rating scale scores and time trade off scores for mild and severe symptoms given by women grouped by use of hormone replacement therapy and severity of symptoms

\begin{tabular}{lrl}
\hline & \multicolumn{2}{c}{ Symptoms } \\
\cline { 2 - 3 } & \multicolumn{1}{c}{ Mild } & \multicolumn{1}{c}{ Severe } \\
\hline Non-users $(\mathrm{n}=21)$ & $0.144(0.20)$ & $0.214(0.08)$ \\
Users (mild symptoms) $(\mathrm{n}=17)$ & $-0.063(0.64)$ & $0.128(0.22)$ \\
Users (severe symptoms) $(\mathrm{n}=25)$ & $-0.029(0.58)$ & $0.281(0.02)$ \\
All ( $\mathrm{n}=63)$ & $0.029(0.38)$ & $0.216(<0.01)$ \\
\hline
\end{tabular}

significant at the $1 \%$ level. In the sulgroup analysis the kappa scores between the results from the two methods were not generally significant. Overall, therefore, these findings indicate that the two methods produced results that were poorly related but not contradictory. These results were not improved by excluding those women who were not prepared to make any time trade off.

\section{QUALITY OF LIFE IMPROVEMENTS}

To measure the benefit obtained from treatment in relation to relief of symptoms (mild, severe, and overall) we calculated average quality of life improvements (measured in life years) per hormone replacement therapy user by using results from the time trade off questions. For example, it was assumed that a woman suffering from mild symptoms would experience an improvement in quality of life of 0.147 $(1-0.853)$ life years over one year of hormone replacement therapy use. Similarly, it was assumed that a woman with severe symptoms would experience an improvement of $0.364(1-0.636)$ life years for one year of hormone replacement therapy use. In calculating average improvements in quality of life associated with use of hormone replacement therapy in women with symptoms we assumed that $90 \%$ of such women experienced relief of symptoms, $5 \%$ experienced side effects, and the other $5 \%$ experienced no change in overall quality of life. With regard to duration of symptoms, it has been reported that $56 \%$ of menopausal women experience acute symptoms related to oestrogen deficiency for between one and five years and that $26 \%$ of women have symptoms for more than five years. ${ }^{10}$ We assumed that hormone replacement therapy users who experienced relief from symptoms did so for an average of four years, regardless of the severity of symptoms. For the 5\% who experienced side effects (average reduction in utility value of 0.3 per year of use of therapy), we assumed that they continued treatment for only six months. This allowed us to calculate an average improvement in quality of life per woman with mild symptoms after use of hormone replacement therapy of 0.522 life years $((0.147 \times 4$ years $\times 0.90)+(-0.3 \times 0.5$ years $\times 0.05))$.

Similarly, the average improvement in quality of life per woman with severe symptoms after use of hormone replacement therapy was estimated at 1.303 life years $((0.364 \times 4$ years $\times 0.90)+(-0.3 \times 0.5$ years $\times 0.05))$. Actual increases in life expectancy (not quality adjusted) after 10 years' use of hormone replacement therapy were calculated to fall between $0 \cdot 10$ (women without hysterectomy) and 0.23 (women with hysterectomy) undiscounted life years (Oxford HRT Study Group, report to the Department of Health, 1992). Adding improvements in quality of life (symptoms overall) yielded QALY gains between $1 \cdot 10$ and $1 \cdot 14$.

\section{Discussion}

For most women, reaching the age of menopause is not viewed with regret or resentment. A recent study undertaken to analyse women's attitudes towards the menopause found that the overwhelming majority of women reported positive or neutral feelings concerning cessation of menses. ${ }^{20}$ However, the most interesting finding from the work described here is that many women feel that quality of life is severely compromised by the presence of menopausal symptoms.

\section{COMPARISON WITH ROSSER SCALE}

Utility values obtained with the time trade off approach $(0.85$ for mild symptoms and 0.64 for severe symptoms) are low when compared with values on the multiattribute Rosser scale: a utility value of 0.85 on the Rosser scale corresponds to disability level VI 
(confined to chair or wheelchair, or requiring help to move around the house) coupled with mild distress, and a utility of 0.68 corresponds to disability level VI coupled with moderate distress. ${ }^{21}$ On the Rosser scale severe distress coupled with severe social disability or slight impairment of performance at work, or both, which would seem to best fit the consequences of severe menopausal symptoms, would produce a utility value of 0.91 . This apparent discrepancy corresponds with the findings of Buxton et al, who compared measurements from the time trade off method and the multiattribute indexes of Rosser and Torrance in a study of health states after mastectomy. ${ }^{22}$ They found that the Rosser values compared poorly with either direct time trade off measurement or the Torrance scale; they also found that both of the multiattribute scales produced values that were considerably higher than the time trade off values, which suggested that the psychosocial morbidity associated with mastectomy was being picked up in the time trade off method but not the multiattribute scales.

In this study psychosocial morbidity may also be an important factor picked up in the time trade off method. Certainly, our description of severe menopausal symptoms, which covered psychological and social as well as physical symptoms of this condition, may have cut closer to the bone with phrases such as "you are failing to cope ... with your home life, with effects on the relationships in your family" and "your complete lack of interest in sex ... may be seriously affecting your marriage." It is possible that our subjects were reacting more to the potential relationship problems brought about by menopausal symptoms, rather than the symptoms themselves.

\section{LIMITATIONS OF MEASUREMENT METHODS}

Although women in our study had been asked to forget about their own experience when answering questions based on the descriptions of mild and severe symptoms, many women, especially those who perceived themselves to have had severe symptoms, found it difficult to be objective in their answers. Often a reply was "Yes, I've had all of those symptoms; it was dreadful. Yes, I would definitely give up three years of life, and have two years without symptoms, rather than having to put up with those symptoms for five years." Similarly, three of the four women who rated quality of life associated with severe symptoms (standard description) as zero on a scale of 0 to 10 -those who felt that it was as bad as death-also considered themselves to have suffered severe symptoms, and all three rated their own quality of life before receiving hormone replacement therapy as zero. This may indicate that women found it difficult to be objective when answering questions based on the standard descriptions. One of these women commented that symptoms she had experienced before using hormone replacement therapy had affected her whole lifestyle, while another said that her whole personality changed when she had symptoms. If objectivity is affected in this way, the quality of life measurements obtained from different samples of women, but based on the same standard descriptions, may differ according to the women's history of symptoms. Women may have responded differently to time trade off questions while actually experiencing symptoms than when in a symptom free state. Sackett and Torrance showed that utility valuations differed between healthy volunteers and patients, although these differences were not large. ${ }^{15}$

One limitation of the rating scale method as used in this study was that there were no indicators of severity along the numerical scale (very poor, poor, average, good, very good, etc), with the consequence that occasionally there were discrepancies between replies given by different women. For example, in response to questions asking women to rate quality of life on a scale from 0 to 10, two replies were "quite good, say 7 " and "not too good, say 7." This problem does not arise with the time trade off approach; however, as noted above, some women were unwilling to consider any trade off between length and quality of life, particularly in relation to the description of mild symptoms. This, and the failure of some women to be objective when answering time trade off questions, may help to explain the greater variability in results obtained with this approach than with the rating scale method, as shown by the confidence intervals in tables I and II. One woman who was unwilling to hypothetically trade off any length of life for an improved quality of life (in relation to both mild and severe symptoms) rated her own quality of life before hormone replacement therapy as 3.5 (on a scale of 0 to 10 ) because she had experienced severe symptoms which had affected her ability to do her job as a lecturer. Another woman who was unwilling to make any trade off (for both mild and severe symptoms) rated her own quality of life both before hormone replacement therapy and during hormone replacement therapy as 10 , because her symptoms were just "an irritant" and weren't bad enough to reduce her quality of life. It is interesting that some of the reasons given for an unwillingness to take a reduction in length of life included "time with my family is too precious" and "my handicapped son needs me to care for him." In other words, the responses included the utility of others as well as themselves. This suggests that the failure of the QALY approach explicitly to incorporate the utilities of people other than the patient may be a legitimate cause for concern.

\section{CONTRIBUTIONS TO VARIABILITY}

Strictly speaking, in the time trade off method the subject should be offered a choice between two alternative health states (of specified duration), both of which are "followed by death." However, given that for most women menopausal symptoms are self limiting, the typical duration of symptoms being less than five years, we felt it unrealistic to include the "followed by death" clause.

Inevitably, some women felt that they would sooner put up with mild menopausal symptoms in the knowledge that these would on the whole be self limiting. On a practical level, this is not unlike the choice which women would be making when deciding whether or not to use hormone replacement therapy. Several women when faced with the choice asked the interviewer, "Does that mean that I would die two years [for example] earlier?" Obviously, deciding now to give up two years of one's life in 20 or 30 years' time is an easier decision than deciding to forgo two years of one's life in the next five years. Women's varying interpretations of the temporal occurrence of trade offs may be another factor contributing to the variability seen in results obtained with this method.

\section{QUALITY ADJUSTMENTS IN ECONOMIC EVALUATION}

Although no consensus has been reached on the methodology or application of QALYs ${ }^{23-29}$ measuring quality of life in chronic, non-life threatening conditions such as the presence of menopausal symptoms may have a role in ensuring that sufferers receive adequate attention. The positive feedback from hormone replacement therapy users shown in this study and others, ${ }^{30}{ }^{31}$ and the indication that menopausal symptoms have a substantial impact on quality of life, justifies the inclusion of quality adjustments when assessing the cost effectiveness of hormone replacement therapy.

Making quality adjustments in our cost effectiveness analysis of hormone replacement therapy (using time 


\section{Public health implications}

- Over $80 \%$ of women experience symptoms at the time of the menopause; in some cases these persist for several years

- This study suggests that quality of life may be severely compromised by the presence of menopausal symptoms

- The use of hormone replacement therapy to relieve symptoms may result in substantial improvements in quality of life

- Measurement of quality of life associated with

common self limiting conditions is important when assessing the need for and outcomes of treatment

- There is a need for a greater availability of appropriate and reliable instruments for measuring quality of life

trade off results) had a profound impact on the resulting costs per QALY (Oxford HRT Study Group, report to the Department of Health, 1992). For example, the cost per life year gained associated with 10 years' treatment of a woman who has had a hysterectomy was estimated at approximately $£ 3200$; after quality adjustments to account for relief of menopausal symptoms the cost per QALY fell to under $£ 400$. It would seem that although there are differences between the different measures of quality of life used in cost-utility analyses, these are of little moment compared with the difference between making quality adjustments and not making them. QALY data are no substitute for, but can provide a valuable aid to, responsible discussion in making resource allocation decisions.

\section{CONCLUSIONS}

The dearth of published information on quality of life associated with many common conditions has been highlighted by several researchers. ${ }^{32-34}$ Others have emphasised the need to measure end points of importance to patients when assessing the benefits of different interventions. ${ }^{35}$ This requires properly validated and appropriate instruments to measure morbidity. This study highlights some of the striking results obtained, as well as some of the problems encountered, when attempting - with widely applied measurement techniques-to measure quality of life changes associated with a common set of symptoms.

We extend our sincere thanks to the staff and patients at the Anderson Clinic in the John Radcliffe Maternity Hospital and to those at the Jericho Health Centre and Beaumont Street general practices who kindly helped us with this work. We are grateful to the Department of Health for financial support.

\section{Appendix}

Mild menopausal symptoms may take one of the following forms:

You will have occasional hot flushes once or twice a day and night sweats which will wake you up occasionally. These may last for between 6 months and 5 or even 10 years.

or

Your concentration and confidence will be poorer than a few years ago, you will cope less well with your job or other work, and you will feel tired some of the time. This may last for between 6 months and 5 or even 10 years.

or

You have noticed that your vagina is rather dry and that this makes sex a little painful. This could continue for a long time, perhaps the rest of your life. You are less interested in sex than you used to be.

Severe menopausal symptoms may take one or all of the following forms:

You will have severe menopausal flushing once or twice every hour with night sweats every night, causing you to lose sleep and often causing you to change your night dress.

You will feel very severe tiredness accompanied by a lack of concentration and confidence so great that you are failing to cope not only with your work but also with your home life, with effects on the relationships in your family.

You will experience a combination of complete disinterest in sex which is only partly because of vaginal dryness. Your lack of interest is so great that you feel even if the vagina was not dry you would not positively choose to have sex. This problem may be seriously affecting your marriage.

1 Hunt $K$, Vessey $M$. The risks and benefits of hormone replacement therapy. Current Obstetrics and Gynaecology 1991;1:21-7.

2 Daly E, Roche M, Barlow D, Gray A, McPherson K, Vessey M. Hormone replacement therapy: an analysis of benefits, risks and costs. $\mathrm{Br}$ Med $\mathrm{Bul}$ 1992;48:368-400.

3 Wilkes HC, Meade TW. Hormone replacement therapy in general practice: survey of doctors in the MRC's general practice research framework. $B M F$ 1991;302:1317-20

4 Coope J, Thomson JM, Poller L. Effects of "natural oestrogen" replacement therapy on meopausal symptoms and blood-clotting. BMF 1975;iv:139-43.

5 Hunt $\mathrm{K}$. Perceived value of treatment among a group of long-term users of hormone replacement therapy. $¥ R$ Coll Gen Pract 1988;38:398-401.

6 Greenblatt RB, Barfield WE, Garner JF, Calk GL, Harrod JP. Evaluation of estrogen, androgen, estrogen-androgen combination, and placebo in treatment of menopause. 9 Clin Endocrinol 1950;10:1547-58.

7 Ditkoff EC, Crary WG, Cristo M, Lobo RA. Estrogen improves psychological function in asymptomatic postmenopausal women. Obstet Gynecol 1991;78: 991-5.

8 Campbell S, Whitehead $M$. Oestrogen therapy and the menopausal syndrome. Clin Obstet Gynaecol 1977;4:31-47.

9 Thomson J, Oswald I. Effects of oestrogen on the sleep, mood and anxiety of menopausal women. $B M \mathcal{F} 1977$;ii:1317-9.

10 McKinlay SM, Jefferys $M$. The menopausal syndrome. $B r f$ Prev Soc Med 1974;28:108-15.

11 Weinstein MC, Schiff I. Cost-effectiveness of hormone replacement therapy in the menopause. Obstet Gynaecol Surv 1983;38:445.

12 Torrance GW. Measurement of health state utilities for economic appraisal: a review. I Health Econ 1986;5:1-30.

13 Fitzpatrick R, Fletcher A, Gore S, Jones D, Spiegelhalter D, Cox D. Quality of life measures in health care. I. Applications and issues in assessment. BMF 1992;305:1074-7.

14 Fletcher A, Gore S, Jones D, Fitzpatrick R, Spiegelhalter D, Cox D. Quality of life measures in health care. II. Design, analysis, and interpretation. $B M$ 1992;305:1145-8.

15 Sackett DL, Torrance GW. The utility of different health states as perceived by the general public. I Chron Dis 1978;31:679-704.

16 Richardson J. Cost utility analysis in health care: present status and future issues. In: Daly J, McDonald I, Willis E, eds. Researching health care designs, dilemmas and disciplines. London: Tavistock Rutledge, 1992.

17 Holland G. Techniques of health status measurement using a health index. London: Office of Health Economics, 1985.

18 Bungay GT, Vessey MP, McPherson CK. Study of symptoms in middle life with special reference to the menopause. $B M F$ 1980;281:181-3.

19 Cohen J. Weighted kappa: nominal scale agreement with provision for scaled disagreement or partial credit. Psychol Bull 1968;70:213-20.

20 Avis NE, McKinlay SM. A longitudinal analysis of women's attitudes toward the menopause: results from the Massachusetts women's health study. Maturitas 1991;13:65-79.

21 Rosser R, Kind P. A scale of valuations of states of illness: is there a social consensus? Int 9 Epidemiol 1978; 7:347-58.

22 Buxton M, Ashby J, O'Hanlon M. Alternative methods of valuing health states. Uxbridge, Middlesex: Brunel University, Health Economics Research Group, 1987.

23 Cubbon J. The principle of QALY maximisation as the basis for allocating health care resources. $f$ Med Ethics 1991;17:181-4.

24 Spiegelhalter DJ, Gore SM, Fitzpatrick R, Fletcher AE, Jones DR, Cox DR Quality of life measures in health care. III. Resource allocation. $B M \mathfrak{F}$ Quality of life meas

25 Harris J. Unprincipled QALYs: a response to Cubbon. $f$ Med Ethics 1991;17:185-8.

26 Wade DT. The "Q" in QALYs. BM7 1991;303:1136-7.

27 Bryan S, Parkin D, Donaldson D. Chiropody and the QALY: a case study in assigning categories of disability and distress to patients. Health Policy 1991;18:169-85.

28 McTurk L. A methodological quibble about QALYs. BMF 1991;302:1601.

29 Quality of life [editorial]. Lancet 1991;338:350-1.

30 Roberts PJ. The menopause and hormone replacement therapy: views of women in general practice receiving hormone replacement therapy. $B r \mathcal{F}$ Gen Pract 1991;41:421-4.

31 Wren BG, Brown L. Compliance with hormonal replacement therapy. Maturitas 1990;13:17-21.

32 Coast J. Reprocessing data to form QALYs. BMf 1992;305:87-90.

33 Gudex C, Kind P. The $Q A L Y$ toolkit. York: Centre for Health Economics, 1988.

34 Williams A. Applications in management. In: Teeling-Smith G, ed. Measuring health: a practical approach. Chichester: John Wiley, 1988: 225 .

35 Kanis JA, Minne WH, Meunier PJ, Ziegler R, Allender E. Quality of life and vertebral osteoporosis. Osteroporosis International 1992;2:161-3.

(Accepted 23 fuly 1993) 